\title{
Sistematização de um Programa de Capacitaçáo ao Professor do Aluno Surdo ${ }^{1}$
}

Systematization of a TRAining Program for TEAchers of DEAF StUdents

\author{
Ana Claudia TENOR ${ }^{2}$ \\ Débora DELIBERATO 3
}

\begin{abstract}
RESUMO: o objetivo desse estudo foi sistematizar ações para a capacitação do professor do aluno surdo por meio da mediação do fonoaudiólogo. Participaram um pai, uma mãe e duas professoras de alunos surdos incluídos. $\mathrm{O}$ estudo foi realizado em três etapas: na primeira etapa os pais e professores foram entrevistados, em seguida foi utilizado um protocolo adaptado e foram realizadas observaçóes em sala de aula sem intervenção. Os dados do protocolo, das observaçóes e das entrevistas foram triangulados e em seguida realizou-se análise de conteúdo, que consistiu em classificação de unidades temáticas. A partir das temáticas identificadas na primeira etapa foi elaborado um programa de capacitaçáo ao professor do aluno surdo que foi desenvolvido na segunda etapa da pesquisa. Concomitante ao grupo de capacitação, a pesquisadora realizou observaçôes e intervençôes na sala de aula dos professores. Os dados dos encontros de capacitação, os registros das observaçóes e filmagens das intervençóes foram triangulados, em seguida realizou-se análise de conteúdo identificando-se unidades temáticas. Na terceira etapa, foi feito o acompanhamento dos professores em sala de aula e identificada as suas opinióes a respeito do programa de capacitação por meio de entrevistas. Os dados das entrevistas foram analisados e classificados em categorias e subcategorias de análise. O programa de capacitação possibilitou aos professores compreenderem as especificidades linguísticas do aluno surdo, a necessidade de adaptação de recursos e estratégias e apontou a necessidade de capacitação das famílias para o uso de suporte a comunicaçáo.
\end{abstract}

PALAVRAS-CHAVE: Educação Especial. Inclusão. Capacitação. Professor. Aluno surdo.

\begin{abstract}
The aim of this study was to systematize actions for training teachers who work with deaf students through the mediation of the speech therapist. The participants were a father, a mother and two teachers of deaf students who are included students. The study was conducted in three stages: during the first stage parents and teachers were interviewed. After that, an adapted protocol was used and observations in the classroom without interventions were performed. Protocol data, observations, and interviews were triangulated and the content was analyzed, which consisted of thematic units' classification. Based on the themes identified in the first stage, a training program was designed for teachers of deaf students, which was developed during the second phase of the research. Simultaneously to the training group, the researcher conducted observations and interventions in the classrooms of the participating teachers. Data from the training meetings, observations records and intervention shootings were triangulated and the content was analyzed, identifying the thematic units. In the third stage, the followup of teachers in their classrooms was carried out and their opinions about the training program were identified through interviews. Interview data were analyzed and classified into categories and subcategories for analysis. This training program enabled the teachers to understand the specific language of their deaf students, the need for resources and adaptation strategies, as well as the need to empower the families to support the use of communication.
\end{abstract}

KEYWORDS: Special Education. Inclusion. Training. Teacher. Deaf Student.

\section{INTRODUÇÃo}

A educação inclusiva tornou-se uma referência a ser assumida pelas redes de ensino, sustentada pelas políticas públicas educacionais. Sob esse enfoque entende-se que o aluno com deficiência deve ter a possibilidade de frequentar a escola regular, participando de todas as ativi-

\footnotetext{
${ }^{1}$ http://dx.doi.org/10.1590/S1413-65382115000300007

${ }^{2}$ Programa de Pós-Graduação em Educação da Faculdade de Filosofia e Ciências da Universidade Estadual Paulista "Júlio de Mesquita Filho”, Marília, SP, Brasil. anatenor@yahoo.com.br

${ }^{3}$ Departamento de Educação Especial e Programa de Pós- Graduação em Educação da Faculdade de Filosofia e Ciências da Universidade Estadual Paulista “Júlio de Mesquita Filho”, Marília, SP, Brasil. delibera@marilia.unesp.br
} 
dades escolares. Nessa perspectiva o professor deve oferecer adaptaçóes e suportes para o aluno a fim de garantir açóes de ensino e aprendizagem de forma efetiva.

Apesar das políticas públicas educacionais advogarem a inclusão, um dos problemas enfrentados nesse processo diz respeito a formação dos professores, pois a maioria não teve formação suficiente para atender essa clientela, sendo necessário pensar em formas de capacitá-los para que possam rever sua prática pedagógica (PADILHA, 2009).

Pesquisas desenvolvidas nos Estados Unidos, Austrália e Canadá também vêm analisando e discutindo as tendências, os modelos e desafios dos programas de formação de professor de aluno surdo (LENIHAN, 2010; FURLONGER et al., 2010; STRYKER, 2011; ERIKSBROPHY; WHITTINGHAM, 2013).

Tratando-se da educação de alunos com surdez, não basta inseri-los em um espaço comum junto a ouvintes, dentro de programas uniformes, sem projetos ou recursos diferenciados. A literatura pontuou a necessidade de um projeto educacional comprometido, que reveja as estratégias pedagógicas, a organização do espaço acadêmico e o currículo, de maneira a contemplar as necessidades do aluno surdo (LACERDA, 2000).

A ausência de um sistema linguístico convencional quer seja por meio da língua de sinais ou língua oral, é um aspecto que vem sendo debatido e tem sido apontado como o responsável pelo fracasso na aprendizagem do aluno com surdez, dificultando a sua permanência na escola regular e seu acesso ao currículo comum (SCHEMBERG; GUARINELLO; MASSI, 2012; ASPILICUETA et al., 2013; SANTANA; GUARINELLO; BERGAMO, 2013).

Nesse contexto, as pesquisas evidenciaram que a criança surda faz uso de sinais caseiros (home signs) para se comunicar com as pessoas ouvintes, no intuito de fugir do isolamento social resultante da ausência de uma língua comum (SANTANA et al., 2008; LIMA; CRUZSANTOS, 2012).

A opção dos pais por uma educação bilíngue exige uma aliança entre família e escola, sendo assim, considerar a questão linguística isoladamente, não é suficiente nas discussóes em torno da inclusão do aluno surdo. Conforme a literatura destacou, o aprendizado de uma língua envolve não apenas a criança surda, mas outras pessoas importantes em sua vida, como pais, famílias, professores e intérpretes (KELMAN, 2010; MARTINS; SOUSA, 2013; MOURA, 2013).

É notório que o processo de inclusão educacional não se sustenta apenas nas açóes do professor em sala de aula, pois demandam uma cadeia de cuidados e a troca de saberes entre os profissionais que atuam em cada segmento dessa cadeia. Nesse sentido, a linguagem, enquanto objeto de estudo da Fonoaudiologia, transversaliza cada elo dessa cadeia e assume papel fundamental na educação inclusiva, por sua função mediadora nos processos de aprendizagem (CÁRNIO et al., 2012).

O desenvolvimento da linguagem requer a capacidade de compreender e utilizar formas e estruturas linguísticas, sendo elemento importante no domínio gradativo da criança sobre o mundo. As crianças em fases iniciais do desenvolvimento da linguagem apresentam capacidades linguísticas e de comunicação limitadas, necessitando de membros mais compe- 
tentes da cultura para exercer e manter interaçóes comunicativas que contribuam para o seu desenvolvimento (VON TETZCHNER et al., 2005; VON TETZCHNER, 2009).

Nessa perspectiva, os estudos reforçaram a importância das interaçóes entre o adulto e a criança, que pode ocorrer entre os pais e a criança ou um tutor e aluno, como uma maneira de oferecer suporte para o desenvolvimento da criança. A função do suporte no desenvolvimento da linguagem é a de incrementar a competência linguística da criança, sua compreensão do uso funcional da linguagem assim como a sua produção de novos sentidos (PUNTAMBEKAR; HUBSCHER, 2005; VON TETZCHNER, 2009).

Deliberato (2013) destacou que parte dos alunos com deficiência apresenta comprometimento na linguagem oral e, por isso, o professor não consegue efetuar o processo de ensino e aprendizagem. A autora considerou que o fonoaudiólogo poderá atuar no processo de construção do planejamento escolar e dos procedimentos relacionados com os processos comunicativos, além disso, ser o mediador entre escola- família- aluno no processo de construção de linguagem e, com isto, favorecer as possibilidades de inclusão nas atividades pedagógicas.

Sameshima (2011) acrescentou ainda, que o trabalho do fonoaudiólogo junto à Educação caminha na direção de construir, em parceria, práticas mais significativas de ensino e aprendizagem. A parceria colaborativa entre fonoaudiólogo e educador, pode ocorrer de forma facilitadora, ao visar às dificuldades de comunicação, linguagem e fala o que poderá potencializar a ação da professora e envolver todo o contexto educacional (BELLO; ALMEIDA; MACHADO, 2012).

Como se percebe, o trabalho de linguagem com a criança surda sofre influência da orientação dos profissionais aos pais bem como da concepção de surdez adotada pela família. O fonoaudiólogo enquanto profissional que atua com as questóes de surdez e linguagem, poderá contribuir com a inclusão da criança surda na escola, por meio de participação em açóes conjuntas com os professores e as famílias de alunos surdos e a inserção desses na rotina escolar. Sendo assim, o objetivo dessa pesquisa foi sistematizar ações para a capacitação do professor por meio da mediação do fonoaudiólogo a respeito das habilidades comunicativas do aluno surdo.

\section{Método}

\subsection{Procedimentos Éticos}

A pesquisa foi aprovada pelo comitê de Ética em Pesquisa sob o protocolo no $0351 / 2011$.

\subsection{Participantes}

Participaram desse estudo um pai, uma mãe e duas professoras que atuavam com aluno surdo incluído, sendo uma da educação infantil e outra do ensino fundamental, de um município do interior de São Paulo.

Foram selecionados dois professores que tinham alunos surdos incluídos, sendo um da Etapa 2 da Educação Infantil e outro do primeiro ano do Ensino Fundamental. Para identificação dos sujeitos foi usado PRO1 (professora do ensino fundamental), PRO2 (professora de 
educação infantil), A1 (aluno surdo), A2 (aluna surda), FA1 (pai do aluno surdo), FA2 (mãe da aluna surda). A coleta de dados foi realizada no período de Fevereiro a Novembro de 2012, na escola de educação infantil e ensino fundamental com os professores selecionados.

\subsection{Características dos ParTiCIPANTES}

A professora do Ensino Fundamental (PRO1) tinha 55 anos de idade e 35 anos de experiência docente, lecionou durante um ano em classe especial, mas sem ter realizado cursos de formação na área de educação especial; era a primeira vez que atuava com aluno surdo (A1). A1, aluno do gênero masculino, tinha seis anos de idade, recebeu o diagnóstico de deficiência auditiva neurossensorial profunda bilateral com dois anos e seis meses, fazia uso de implante coclear há quatro anos e do sistema FM em sala de aula há seis meses. A1 compreendia ordens verbais simples e os comandos rotineiros da escola sem o apoio de gestos, comunicava-se por meio de gestos espontâneos, vocalizaçóes e dramatizaçóes. $\mathrm{O}$ aluno apresentava pouco contato visual com o interlocutor e não mantinha atenção visual enquanto a professora ensinava as tarefas em sala de aula.

A professora de Educação Infantil (PRO2) tinha 32 anos de idade e dois anos de experiência em sala de aula, durante sua graduação em pedagogia fez um curso de extensão em Libras de 40 horas e atuava pela primeira vez com a aluna surda (A2). O aluno A2, do gênero feminino, cinco anos de idade, teve o diagnóstico de deficiência auditiva neurossensorial profunda bilateral com quatro anos de idade, fazia uso de implante coclear há um ano e sete meses. A2 detectava sons, mas não compreendia ordens verbais simples e os comandos rotineiros da escola sem o apoio de gestos, fazia uso da leitura orofacial, comunicava-se por meio de gestos espontâneos e vocalizaçóes. A2 apresentava atenção visual ao interlocutor, mas não a mantinha enquanto a professora ensinava as tarefas em sala de aula.

\subsection{LOCAL E PERÍODO}

O estudo foi desenvolvido em uma cidade de pequeno porte do interior do estado de São Paulo. A coleta de dados foi realizada no período de fevereiro a novembro de 2012.

\subsection{Organização do TRABALHo}

O programa de capacitação do professor do aluno surdo foi dividido em três etapas, norteado pelo programa de atuação nas escolas, preconizado por Deliberato (2009, 2013), sofrendo adequaçóes para atender as especificidades do aluno e a necessidade de formação do professor.

\subsubsection{Primeira etapa}

A primeira etapa se caracterizou pelo contato e estabelecimento de vínculo da pesquisadora com as famílias e professores dos alunos, a fim de se identificar suas necessidades para elaborar um plano de atuação a ser desenvolvido na segunda etapa. Nesta etapa, foram elaborados e utilizados três instrumentos de pesquisa: dois roteiros de entrevistas semiestruturadas, um direcionado a professores e outro à família e, um protocolo para avaliação de habilidades 
comunicativas em ambiente escolar com o professor, adaptado a partir da proposta de Paula (2007). Além desses instrumentos foram realizadas observaçóes do aluno e professor em sala de aula por meio de filmagens e anotaçóes em caderno de registro.

\subsubsection{Procedimento de Coleta de dados da PRimeira ETAPA}

Na primeira etapa foram realizadas observaçóes do professor e aluno em sala de aula sem intervenções. A pesquisadora fez apenas uma observação na sala de educação infantil e no ensino fundamental com duração de uma hora, antes de entrevistar os professores e preencher o protocolo para avaliação de habilidades comunicativas do aluno surdo. Os roteiros de entrevistas e o protocolo foram feitos individualmente em horários pré-agendados na escola.

\subsubsection{Procedimento DE ANÁlISE DA PRIMEIRA ETAPA}

As entrevistas foram transcritas, o texto foi adequado as normas da Língua Portuguesa e, também foi utilizado sinais das normas de Marcuschi (1986). Os dados obtidos do protocolo e registros das observaçóes em sala de aula foram incorporados as transcriçóes, constituindo um texto único, originando os seguintes temas e subtemas de análise, conforme Bardin (2004): 1) Habilidades de comunicação: compreensão e expressão; opinião a respeito de Libras; 2) Recursos: recursos para compreensão, recursos para expressão; 3) Estratégias: estratégia para o ensino; 4) Aprendizagem: percepção e opiniâo; 5) Recursos tecnológicos: implante coclear, sistema FM; 6) Família: percepção do envolvimento, participação e expectativas.

\subsubsection{SEgunda ETAPA}

O programa de capacitação com os professores ocorreu por meio de oito encontros. Sendo assim, os temas identificados na primeira etapa foram organizados em forma de caderno de conteúdo, segundo o modelo adotado por Ferreira (2006), e apresentado aos professores no primeiro encontro de capacitação para iniciar as discussões a respeito das habilidades e necessidades do aluno surdo e demais conteúdos necessários para a atuação do professor com esse aluno na rotina de sala de aula. No total, foram elaborados sete cadernos de conteúdo que a pesquisadora entregava aos participantes no decorrer dos encontros, para disparar as discussóes. Durante a segunda etapa a pesquisadora construiu as mediaçóes em parceria com os professores e realizou intervençóes nas salas de aula a partir das discussóes nos encontros de capacitação junto aos professores. Sendo assim, as intervençóes foram previamente organizadas, planejadas e discutidas no grupo com os professores e após a atuação da pesquisadora em sala de aula, esta retornava ao grupo de capacitação para discutir a respeito das intervençóes realizadas. Para a segunda etapa foram utilizados os seguintes instrumentos de pesquisa: os cadernos de conteúdo que subsidiaram as discussóes com o professor, o caderno de registro para anotaçóes das observaçóes e mediaçóes da pesquisadora em sala de aula, a filmagem para registrar situaçóes em sala de aula, a gravação das discussóes com o grupo de capacitação. 


\subsubsection{Procedimento de coleta de dados da SEgunda ETaPa}

Nessa etapa, inicialmente a pesquisadora fez observaçóes em sala de aula e discussóes no grupo de capacitação e posteriormente, deu início as mediaçóes por meio de contos de histórias, fazia anotaçóes no caderno de registro e retornava aos encontros de capacitação apresentando os temas e subtemas previamente elencados; depois ouvia a opinião dos professores. Foram realizados oito encontros de capacitação no horário de trabalho pedagógico coletivo (HTPC), treze observaçóes e doze mediaçôes na sala de educação infantil, dez observações e treze mediaçóes na sala de ensino fundamental.

\subsubsection{Procedimentos De INTERVENÇÓES}

As intervençốes da pesquisadora constaram de discussóes durante o grupo de capacitação e mediaçóes por meio de contos de histórias em sala de aula. Os temas das histórias foram selecionados em conjunto com os professores durante as discussóes em grupo. Seguindo as recomendaçóes de Thomson (2012) a pesquisadora apresentou três vezes cada conto, em dias diferentes, diversificando os recursos e as estratégias. Após a autorização dos pais dos alunos surdos, a partir da quarta mediação, a pesquisadora começou a sensibilizar as escolas para o ensino de língua de sinais e a apresentar os sinais de libras referentes aos contos de histórias nas duas escolas. A pesquisadora usou a comunicação bimodal, pois narrava a história oralmente e simultaneamente fazia sinais em libras referentes aos personagens, verbos e léxico.

\subsubsection{Procedimento DE ANÁLISE DA SEGUNDA ETAPA}

As discussóes durante os encontros foram gravadas, o material foi transcrito e feita análise de conteúdo conforme Bardin (2004), sendo elencados temas e subtemas de análise, organizados em forma de cadernos de conteúdo, segundo o modelo proposto por Ferreira (2006). Os dados provenientes dos cadernos de conteúdo, os registros das observaçóes e filmagens das atividades de intervençóes foram triangulados conforme Trivños (1992), gerando oito temas e seus respectivos subtemas: 1- comunicação: compreensão e expressão; 2- aluno surdo: implicaçóes da surdez, desenvolvimento, comportamento; 3- ensino: estratégias para o ensino e recursos; 4- aprendizagem: compreensão da tarefa, surdez e letramento; 5- avaliação: educação infantil, ensino fundamental; 6- recursos tecnológicos: aparelho de amplificação sonora individual, implante coclear, sistema de frequência modulada; 7-família: envolvimento, expectativa, aceitação da surdez, orientação familiar, família extensiva; 8- escola: parceria escola e profissionais, orientação escolar.

\subsubsection{TERCEIRA ETAPA}

$\mathrm{Na}$ terceira etapa foi feito um acompanhamento dos professores para que os mesmos pudessem relatar a experiência dos encontros e opinar a respeito do programa de capacitação após a finalização do grupo de discussão e mediação da pesquisadora na sala de aula. Esta etapa foi feita por meio do uso do roteiro de entrevista e observação na sala de aula sem intervenção. 


\subsubsection{Procedimento de ANÁlise}

As entrevistas com os professores foram gravadas e feita análise de conteúdo segundo Bardin (2004). Foram identificadas quatro categorias e suas respectivas subcategorias: 1- grupo de discussão: percepção do professor; 2- participação do fonoaudiólogo: opinião do professor; 3- recursos e estratégias: adaptação de histórias, dramatização, inserção de Libras; 4- comunicação do aluno após a capacitação do professor: mudança na comunicação; opinião do professor.

\section{Resultados E discussáo}

A seguir serão apresentados os resultados de cada etapa da proposta do programa de capacitação: contato com a escola, grupo de capacitação, mediação do pesquisador em sala de aula e o seguimento dos professores.

Para sistematização de um programa de capacitação ao professor do aluno com surdez foi fundamental na primeira etapa o fonoaudiólogo ouvir previamente os professores, entender as necessidades linguísticas de cada aluno e a partir da identificação dessas necessidades, pensar e elaborar em conjunto com o professor a respeito de recursos e estratégias a serem implementadas em sala de aula.

Os temas e subtemas identificados na primeira etapa foram analisados e discutidos para serem incorporados na segunda etapa, constituindo-se então em temas norteadores para os encontros de capacitação com os professores. Cabe destacar que entre as unidades temáticas identificadas na primeira etapa será apresentado o tema habilidades de comunicação por ser este, o tema mais recorrente nas discussóes e ter gerado a necessidade de capacitar o professor para identificação das habilidades e necessidades comunicativas do aluno surdo.

Os exemplos a seguir mostram relatos verbais dos participantes referentes às unidades temáticas identificadas na primeira etapa.

\subsection{HaBILIDADES DE COMUNICAÇÁO: COMPREENSÁO E EXPRESSÃO}

A identificação das habilidades de compreensão e expressão da criança surda a partir da percepção da família e do professor possibilita orientá-los adequadamente a respeito do desenvolvimento da linguagem, favorecendo, assim, açóes conjuntas que possam levar a uma aprendizagem efetiva (VON TETZCHNER, 2009; DELIBERATO, 2013).

Os exemplos a seguir foram obtidos durante as entrevistas com FA1 e FA2, tendo como objetivo justamente entender as habilidades comunicativas das crianças surdas deste estudo.

\section{Exemplo1: Entrevista realizada com FA1}

Pe: Você está conseguindo se comunicar com ele?

FA1: É (+) eu me comunico com ele, mas é pouco. É sempre por gesto.

Pe: Sempre por gesto FA1?

FA1: Tento falar, falo, mas falo tudo com gesto.

Pe: Hoje em dia de que forma o A1 mais se comunica (+) por gesto, gesto e fala ou língua de sinais?

FA1: Ele grita e faz gesto. 
Exemplo 2: Entrevista realizada com FA2

Pe: Você consegue se comunicar com a A2?

FA2: Com a A2 sim.

Pe: E como que você se comunica com ela no dia a dia?

FA2: Então eu tento falar com ela olhando bem nela, porque ela entende.

Pe: E sinais?

FA2: Pouco sinal. É (+) sinal na verdade só três sinais, que banho, escola e comer.

Pe: De que forma ela se comunica mais /.../?

FA2: Ela usa gesto e fala junto. Porque ela fala e usa os dois.

Os relatos verbais dos pais nos Exemplos 1 e 2 evidenciaram que diante da falta de um sistema de representação linguística, os filhos surdos comunicavam-se por meio de gestos caseiros e vocalizaçóes. Esse sistema de comunicação apesar de possibilitar a comunicação entre a criança e as pessoas que com ela convivem, é considerado limitado, pois se restringe a atender às suas necessidades primárias e a tópicos diretamente relacionados com a realidade da criança (SANTANA et al., 2008; LIMA; CRUZ- SANTOS, 2012).

A seguir, são apresentados trechos das entrevistas realizadas com as professoras referentes a temática habilidades de comunicação, as quais não diferiram das percepçóes dos familiares. Observou-se que a comunicação com os alunos surdos ocorria por meio de uma linguagem não simbólica, ou seja, faltava um sistema de representação:

\section{Exemplo 3- Entrevista realizada com PRO1}

Pe: A compreensão dele como é, ele compreende todos os comandos, todas as ordens?

PRO1: A maior parte. Quando a atividade é na folha eu explico, mostro,vou apontando, também através de gestos.

Pe: E para ele se expressar é mais $(+)$

PRO1: Mais gestual. /.../ Assim, ele emite alguns sons, algumas vogais /.../. O meu nome, na segunda- feira, eu falei aí ele repetiu "Is".

\section{Exemplo 4- Entrevista realizada com PRO2}

PRO2: Ela se comunica muito pouco, ela dá um toque na gente $\mathrm{E}$ aponta. /.../ Às vezes ela faz aquele barulhinho, aquele sonzinho.

Pe: Como que é a compreensão dela? Você acha que ela compreende as ordens, os comandos das tarefas da apostila, ou as tarefas da rotina da escola?

PRO2: Ela compreende porque ela realiza. Agora fica difícil para eu conseguir entender, porque sempre tudo é feito em grupo.

Os relatos das professoras (PRO1, PRO2) permitiram observar que os alunos surdos comunicavam-se na escola por meio de gestos, vocalizaçóes e apontamentos, evidenciando que estavam em processo de construção de uma língua e necessitavam, portanto, da mediação de um adulto para fornecer o modelo e, assim, propiciar o seu desenvolvimento.

Para construção de uma língua, a criança precisa de um suporte de mediação constante, mas para isso, é preciso capacitar o professor. Nessa perspectiva, von Tetzchner (2009) considerou que a função do suporte no desenvolvimento de linguagem da criança é a de incrementar a sua competência linguística, sua compreensáo do uso convencional da linguagem, assim como a sua produção criativa de novos sentidos. 
$\mathrm{Na}$ segunda etapa a pesquisadora atuou concomitantemente em sala de aula e nos encontros de capacitação com os professores. Os resultados dessa etapa ilustram momentos de observaçóes e mediaçóes da pesquisadora em sala de aula bem como os relatos verbais dos professores durante as discussões nos encontros de capacitação. Será apresentado a seguir o tema ensino, por estar relacionado com os aspectos linguísticos e educacionais do aluno surdo.

\subsection{ENSINO: ESTRATÉGIAS PARA O ENSINO, RECURSOS}

Para discutir a respeito de estratégias de ensino tanto a alunos ouvintes como surdos, é importante identificar e conhecer as práticas pedagógicas adotadas e a concepção de linguagem subjacente a elas. Assim como para as crianças ouvintes, também para as surdas o ensino da Língua Portuguesa tem se fundamentado na concepção de linguagem como instrumento de comunicação. Nessa concepção, a língua é vista como um código, um conjunto de regras que responde pela organização dos sons, das palavras e das estruturas frasais. Subjacente a essa concepção, parece estar a pressuposição de que, conhecendo as regras da língua, os alunos podem vir a usá-la adequadamente. No exemplo a seguir, pode-se perceber esse aspecto.

Exemplo 7-Comentário de PRO1 durante o encontro de capacitação a respeito das estratégias por ela adotada no conto da história "João e o Pé de Feijāo"

Pe: Qual foi a estratégia, que você utilizou ao contar a história: "Joáo Pé de Feijão"? Se eu interpretei bem, você estava trabalhando consciência fonológica, consciência silábica.

PRO1: É (+) sonoro.

Pe: GI-GAN-TE, silabando e batendo palma.

PRO1: Silábica e sonora. Eu li na segunda- feira três vezes, ontem li duas porque daí você vai trabalhando a memorização do conto, trabalhando a memória para eles adquirirem o repertório.

Foi possível observar no Exemplo 7 que a professora não tinha conhecimento suficiente a respeito das especificidades e necessidades do aluno surdo e adotava uma prática pedagógica planejada para o ouvinte, trabalhando com as habilidades fonológicas, enfatizando nessa atividade a consciência silábica, pois pronunciava a palavra gigante silabando e batendo palmas para cada sílaba emitida.

No que diz respeito à organização do trabalho pedagógico para o aluno surdo, Lacerda (2000) reforça a necessidade de o professor pensar cuidadosamente nas metodologias a serem implementadas, para que os insucessos pedagógicos não sejam falsamente justificados por um desinteresse ou desatenção por parte da criança surda.

Durante a etapa 2 a pesquisadora buscou então oferecer um modelo de suporte ao professor por meio de recursos visuais e também sensibilizar a escola, envolvendo os alunos e a professora para o ensino de Libras, conforme ilustra o Exemplo 8.

Exemplo 8-Mediação da pesquisadora na educação infantil durante o conto e reconto "Chapeuzinho Vermelho"

A atividade foi desenvolvida na escola de educação infantil, com a participação dos alunos ouvintes, aluna surda (A2) e professora de educaçáo infantil (PRO2). A pesquisadora usou a comunicaçáo bimodal, pois se tratava de inclusão de uma aluna surda em sala de ouvintes, sem o apoio do intérprete de Libras. Era a segunda vez que a pesquisadora apresentava o conto Chapeuzinho Vermelho" à classe. Nesse dia usou como recursos uma prancha de papeláo contendo o cenário de floresta, e fez uso da prancha com as sequências de figuras da história, confeccio- 
nadas por meio do PCS. A pesquisadora posicionou a prancha na mesa da professora, a frente da sala, colava as figuras e narrava oralmente a história. Em seguida a pesquisadora narrou oralmente e fez os sinais dos personagens, verbos e demais léxico referente a história. Enquanto a pesquisadora narrava a história, $\mathrm{PRO} 2$ sentou-se em uma cadeira ao lado da prancha e auxiliava a pesquisadora repetindo os sinais apresentados e oferecendo o modelo a classe. Ao finalizar o conto de história a pesquisadora perguntou a classe os sinais apresentados referente aos personagens e vocabulário. Nessa atividade houve interação e participação de $\mathrm{PRO} 2$, alunos ouvintes e aluna surda. A pesquisadora ofereceu um modelo de suporte ao professor a ser utilizado com a aluna surda durante o conto por meio do uso de recursos visuais.

Conforme a literatura o suporte no desenvolvimento da linguagem é dialógico e representa uma adaptação no apoio às capacidades e habilidades de cada criança. A sua função é a de incrementar a competência linguística da criança, sua compreensão do uso funcional da linguagem, assim como a sua produção criativa de novos sentidos (PUNTAMBEKAR; HUBSCHER, 2005; VON TETZCHNER, 2009).

$\mathrm{Na}$ terceira etapa a pesquisadora fez um acompanhamento dos professores e por meio de entrevistas evidenciou as suas opiniōes a respeito do programa de capacitação. As entrevistas foram gravadas, analisadas e identificadas as seguintes categorias e subcategorias de análises conforme Bardin (2004): 1- grupo de discussão: percepção do professor; 2- participação do fonoaudiólogo: opinião do professor, 3- recursos e estratégias: adaptação de histórias, dramatização, inserção de Libras; 4-comunicação do aluno após a capacitação do professor: opinião do professor. Foram selecionadas para exemplificação as temáticas grupo de discussão, recursos e estratégias, comunicação do aluno após o programa de capacitação.

Os relatos verbais nos Exemplos 9 e 10 mostram a opinião dos professores a respeito dos grupos de discussão.

\section{Exemplo 9- Entrevista realizada com PRO1}

PRO1: Então, achei enriquecedor, isso influencia totalmente as questôes do aluno surdo, eu aprendi muito, eu desconhecia totalmente os costumes do aluno surdo.

\section{Exemplo 10- Entrevista realizada com PRO2}

PRO2: Eu achei ótimo, eu me senti assim amparada, tendo a possibilidade de poder contar com sua ajuda, nas dúvidas, ainda mais que foi o primeiro ano que eu peguei aluno com deficiência auditiva, eu achei ótimo, maravilhoso o seu apoio.

Foi possível perceber por meio dos relatos dos professores nos Exemplos 9 e 10, que o programa de capacitação auxiliou o professor a conhecer o aluno surdo. PRO1 considerou o programa enriquecedor, pois desconhecia as questóes referentes a surdez e PRO 2 sentiu-se amparada com o apoio do fonoaudiólogo.

Os Exemplos 11, 12, 13 e 15 ilustram os temas recursos e estratégias.

Os professores relataram que os recursos e estratégias empregados, como as adaptações de histórias infantis e a dramatização auxiliaram a compreensão do aluno surdo, conforme os Exemplos 11 e 12.

Pe: Você acha que essas adaptaçóes auxiliaram de alguma forma a compreensão do A1?

PRO1: Eu acho, ajudou. 
Exemplo 12- PRO 2

PRO2: Ah, essas adaptaçóes foram essenciais para aprendizagem, para haver a aprendizagem. Facilitou a MINHA aprendizagem e a aprendizagem a A2.

Pe: E o que você achou da dramatizaçáo /.../?

PRO2: A dramatização sem dúvida é importante também. Porque se ela não está ouvindo ou se está ouvindo um pouco, a dramatização é o visual, o visual é tudo para ela. Então a dramatização é importante.

Em relação a apresentação dos sinais de Libras durante os contos de histórias, a professora do ensino fundamental mencionou que foi tardia, já a professora de educação infantil considerou que foi importante e essa atividade passou a fazer sentido para a aluna surda, conforme os Exemplos 13 e 14.

\section{Exemplo 13-PRO1}

Pe:O que você achou da introdução desses sinais básicos, dos personagens (+).

PRO1: Eu achei assim, um pouco tardio.

Exemplo 14- PRO 2

PRO2: /..../ No final do ano, agora que a mãe autorizou e toda aquela burocracia dos gestos, que gente se sentiu mais a vontade. /.../ Que até então estava meio sem sentido, a gente falava ela não ouvia. Eu digo, se ouvia, não ouvia, mas não estava dando retorno.

\section{Conclusão}

A proposta deste estudo foi sistematizar açóes para a capacitação do professor do aluno surdo por meio da intervenção do fonoaudiólogo a respeito das habilidades comunicativas do aluno surdo. As famílias desse estudo foram convidadas a participar dos encontros de discussões junto aos professores, mas não houve adesão por parte dessas, sendo assim, o estudo foi conduzido com os professores participantes. Para a viabilização dessa proposta foram estabelecidas três etapas durante o programa de capacitação para atender os seguintes objetivos específicos: identificar temas para a capacitação do professor do aluno surdo (primeira etapa); a partir das temáticas identificadas na primeira etapa elaborar um programa de capacitação ao professor por meio de encontros de capacitaçóes, além da mediação do fonoaudiólogo em sala de aula (segunda etapa); acompanhar os professores e identificar a sua opiniáo a respeito do programa de capacitação por meio de entrevistas (terceira etapa).

Ao término do programa de capacitação os professores consideraram que os recursos e estratégias empregados, como as adaptaçóes de histórias infantis e a dramatização auxiliaram a compreensão do aluno surdo. No que diz respeito a apresentação dos sinais de Libras durante os contos de histórias, a professora do Ensino Fundamental mencionou que foi tardia, já a professora de Educação Infantil ressaltou que foi importante e considerou que essa atividade passou a fazer sentido para a aluna surda. Constatou-se que o programa de capacitaçáo sensibilizou os professores para as especificidades linguísticas do aluno com surdez bem como a necessidade de adaptação recursos e estratégias para o ensino desse aluno. Evidenciou-se também a necessidade de capacitar as famílias para as questóes linguísticas da criança surda, por meio da oferta de um modelo de suporte a comunicação entre pais ouvintes e filhos surdos. 


\section{REFERENCIAS}

ASPILICUETA, P. et al. A questão linguística na inclusão escolar de alunos surdos: ambiente regular inclusivo versus ambiente exclusivamente ouvinte. Revista Brasileira de Educação Especial, Marília, v.19, n.3, p.395-410, 2013.

BARDIN, L. Análise de conteúdo. Tradução de Lis Reto e Augusto Pinheiro. Lisboa: Edições 70, 2004.

BELLO, S.F.; ALMEIDA, M.A.; MACHADO, A.C. Parceria colaborativa entre fonoaudiólogo e professor: análise dos diários reflexivos. Revista Psicopedagogia, v.29 n.88, p.46-54, 2012.

CÁRNIO, M.S. et al. Escola em tempo de inclusão: ensino comum, educação especial e ação do fonoaudiólogo. Revista Distúrbios da Comunicação, São Paulo, v.24, n.2, p.249-256, 2012.

DELIBERATO, D. Comunicação alternativa na escola: habilidades comunicativas e o ensino da leitura e escrita. In: DELIBERATO, D.; GONÇALVES, M. J.; MACEDO, E.C. (Org.).Comunicação alternativa: teoria, prática, tecnologias e pesquisa. São Paulo: Memnon Ediçóes Científicas, 2009. p.235-243.

DELIBERATO, D. Comunicação alternativa na escola: possibilidades para o ensino do aluno com deficiência. In: ZABOROSKI, A.P.; OLIVEIRA, J.P. (Org.). Atuaçâo da fonoaudiologia na escola: reflexóes e práticas. Rio de Janeiro: Wak Editora, 2013, p.71- 90.

ERIKS-BROPHY, A.; WHITTINGHAM, J. Teachers' perceptions of the inclusion of children with hearing loss in general education settings. American Annals of the deaf, v.158, n.1, p.63-97, 2013.

FERREIRA, G.C. Programa de educação familiar continuada em linguagem: orientaçôes a pais de crianças com atrasos globais de desenvolvimento. 2006. 165f. Dissertação (Mestrado em Educação) - Faculdade de Filosofia e Ciências de Marília, Universidade Estadual Paulista, Marília, 2006.

FURLONGER, B. et al. A new approach to training teachers to meet the diverse learning needs of deaf and hard-of-hearing children within inclusive Australians schools. International Journal of Inclusive Education, v.14, n.3, p.289-308, 2010.

KELMAN, C. A. Dilemas sobre o implante coclear: implicaçóes linguísticas e pedagógicas. INES, Rio de Janeiro, n.33, p.33- 49, 2010.

LACERDA, C. B. F. A inserção da criança surda em classe de crianças ouvintes: focalizando a organização do trabalho pedagógico. In: REUNIÃO ANUAL DA ANPED, 23., 2000, Caxambú. Anais eletrônicos. Caxambú: ANPED, 2000. Disponível em: <www.anped.org.br/23/ textos/1518t.pdf>. Acesso em: 10 jul. 2014.

LENIHAN, S. Trends and challenges in teacher preparation in deaf education. The Volta Review, v.110, n.2, p.117-128, 2010.

LIMA, E. R. S.; CRUZ-SANTOS, A. Aquisição dos gestos na comunicação pré- lingüística: uma abordagem teórica. Revista Sociedade Brasileira de Fonoaudiologia, v.17, n.4, p.495-501, 2012.

MARCUSCHI,L.A. Análise da conversação. São Paulo: Ática, 1986.

MARTINS, D.A.; SOUSA, S.F. Educação infantil e aquisição da linguagem: contrapontos de uma política inclusiva e bilíngue para surdos. In: ALBRES, N.A.; NEVES, S.L.G. (Org.). Libras em estudo: política educacional. São Paulo: FENEIS, 2013. p.71-96.

MOURA, M.C. Surdez e Linguagem. In: LACERDA, C.B.F.; SANTOS, L.F. (Org.). Tenho um aluno surdo, e agora? Introdução a Libras e educação de surdos. São Carlos: EDUFSCar, 2013. p.13-26. 
PADILHA, A.M.L. Desafios para a formação de professores: alunos surdos e ouvintes na mesma sala de aula? In: LODI, A.C.B.; LACERDA, C.B.F. (Org.). Uma escola, duas línguas: letramento em língua portuguesa e língua de sinais nas etapas inciais de escolarização. Porto Alegre: mediação, 2009. p.114126.

PAULA, R. Desenvolvimento de um protocolo para avaliação de habilidades comunicativas de alunos nãofalantes em ambiente escolar. 2007. 148f. Dissertação (Mestrado em Educação) - Faculdade de Filosofia e Ciências, Universidade Estadual Paulista, Marília, 2007.

PUNTAMBEKAR, S.; HUBSCHER, R. Tools for scaffolding students in a complex learning enviromment: What have we gained and what we have missed? Educational Psychologist, v.40, n.1, p.1$12,2005$.

SANTANA, A.P. et al. O estatuto simbólico dos gestos no contexto da surdez. Psicologia em Estudo, Maringá, v.13, n.2, p.297-306, 2008.

SANTANA, A.P.; GUARINELLO, A. C.; BERGAMO, A. A clínica fonoaudiológica e a aquisição do português como segunda língua para surdos. Revista Distúrbios da Comunicação, São Paulo, v.25, n.3, p.440-451, 2013.

SAMESHIMA, F.S. Capacitação de professores por meio de sistemas de comunicação suplementar e alternativa. 2011. 180f. Tese (Doutorado em Educação) - Faculdade de Filosofia e Ciências, Universidade estadual Paulista, Marília, 2011.

SCHEMBERG, S.; GUARINELLO, A. C.; MASSI, G. O ponto de vista de pais e professores a respeito das interaçóes linguísticas de crianças surdas. Revista Brasileira de Educação Especial, Marília, v.18, n.1, p.172-32, 2012.

STRYKER, D.S. Baseline data on distance education offerings in deaf education teacher preparation programs in the United States. American Annals of the Deaf, v.155, n.5, p.550-561, 2011.

THOMSON, A. L. A. Contação de histórias. Revista do Professor, v.28, n.109, p.13-19, 2012.

TRIVIÑOS, A.N.S. Introdução à pesquisa em ciências sociais: a pesquisa qualitativa em educação. São Paulo: Atlas, 1992.

VON TETZCHNER, S. et al. Inclusão de crianças em educação pré- escolar regular utilizando comunicação suplementar e alternativa. Revista Brasileira de Educação Especial, Marília, v.11, n.2, p.151-184, 2005.

VON TETZCHNER, S. Suporte ao desenvolvimento da comunicação suplementar e alternativa. In: DELIBERATO, D.; GONÇALVES, M.J.; MACEDO, E.C. (Org.). Comunicação alternativa: teoria, prática, tecnologia e pesquisa. São Paulo: Memnon Edições Científicas, 2009. p.14- 27.

Recebido em: 08/10/2014

Aprovado em: 16/05/2015 
TENOR, A.C. \& DELIBERATO, D. 